\title{
The Relationship Between Primary Sleep Disorders and Temporomandibular Disorders: An 8-Year Nationwide Cohort Study in South Korea
}

\author{
Seon-Jip Kim (1) ${ }^{1,2}$ \\ Sang Min Park (iD) ${ }^{3,4}$ \\ Hyun-Jae Cho (iD ${ }^{1,2, *}$ \\ Ji Woon Park $\mathbb{D}^{2,5,6, *}$
}

'Department of Preventive Dentistry and Public Oral Health, School of Dentistry,

Seoul National University, Seoul, Republic of Korea; ${ }^{2}$ Dental Research Institute, Seoul National University, Seoul, Republic of Korea; ${ }^{3}$ Department of Family Medicine, Seoul National University Hospital, Seoul, Republic of Korea; ${ }^{4}$ Department of Biomedical Sciences, Seoul National University Graduate School, Seoul, Republic of Korea; ${ }^{5}$ Department of Oral Medicine and Oral Diagnosis, School of Dentistry, Seoul National University, Seoul, Republic of Korea; ${ }^{6}$ Department of Oral Medicine, Seoul National University Dental Hospital, Seoul, Republic of Korea

*These authors contributed equally to this work
Background: While evidence is accumulating to propose a specific contribution of sleep disorders and low quality sleep in the pathogenesis of temporomandibular disorders (TMD), management of primary sleep disorders in the process of preventing and treating TMD still remains scientifically unsupported.

Objective: To investigate the association of primary sleep disorders with TMD risk in South Korea.

Patients and Methods: This study was based on the National Health Insurance ServiceNational Health Screening Cohort (NHIS-HEALS) of South Korea with 468,882 participants. After excluding participants diagnosed in 2002, those with a diagnosis of a primary sleep disorder in 2003-2005 were recruited. All participants diagnosed with TMD between January 1, 2006 and December 31, 2013 received follow-up. Cox proportional hazards regression was performed to determine the adjusted hazard ratios (aHR) and 95\% confidence interval (CI) for TMD according to the presence or absence of a primary sleep disorder diagnosis.

Results: After adjusting for all covariates, primary sleep disorder patients had a $44 \%$ higher risk for TMD compared with non-sleep disorder participants (aHR 1.44, 95\% CI 1.02-2.04). The incidence rate of TMD was nearly twice as high in participants with sleep disorders compared with those without (6.08 vs 3.27 , per $10^{4}$ person-years). In subgroup analysis, an association was observed with those over 60 years old or who frequently exercised physically.

Conclusion: Primary sleep disorders could be an important independent risk factor for the initiation and maintenance of TMD. Patients with sleep disorders should be monitored for possible co-occurrence of TMD-related symptoms that could aggravate sleep disorders in turn. Keywords: sleep disorders, temporomandibular disorders, cohort studies, epidemiology

\section{Introduction}

Department of Oral Medicine and Oral Diagnosis, School of Dentistry, Seoul National University, I0I Daehak-Ro, Jongno-Gu, Seoul, 03080, Republic of Korea

Tel +82 2-2072-49/2

Email ankara0I@snu.ac.kr

Hyun-Jae Cho

Department of Preventive Dentistry and Public Oral Health, School of Dentistry,

Seoul National University, I0I Daehak-

Ro, Jongno-Gu, Seoul, 03080, Republic of Korea

Tel +82 2-740-8677

Email stbluewi@snu.ac.kr
Temporomandibular disorders (TMD) is a common musculoskeletal pain syndrome of the orofacial region with a prevalence as high as $8-15 \%$ in the general population, representing a significant public health issue. TMD is mainly known as a clinical dysfunction accompanied by pain and movement limitation of the temporomandibular joint (TMJ) and surrounding musculature. ${ }^{1}$ It is a major cause of nonodontogenic pain in the orofacial region and is known to lower sufferers' quality of life notably, especially when it is accompanied by various comorbidities such as chronic widespread pain, psychological, and gastrointestinal disorders. ${ }^{2,3}$ Many physical and psychological factors, when repeatedly occurring, are known to trigger the initiation of TMD and affect its prognosis. Among those disturbed and 
unrefreshing sleep has also been reported as a major modulating factor. ${ }^{4,5}$ Restorative sleep is necessary to maintain physiologic homeostasis, hence inadequate sleep, both qualitatively and quantitatively, has been associated with various adverse health outcomes encompassing cardiovascular, endocrinologic, psychological diseases and also cancer. $^{6-14}$ Disturbed sleep is a common characteristic among pain disorders such as low back pain, fibromyalgia, and cancer pain. ${ }^{15-17}$ The relationship between pain and sleep is known to be bidirectional with poor sleep enhancing the perception of pain and pain resulting in disrupted sleep. ${ }^{18,19}$ The duration of pain is also known to influence the relationship, with this effect especially being prominent in chronic pain patients. ${ }^{20}$ Previous studies report sleep problems in $40-88 \%$ of patients depending on the specific chronic pain condition. ${ }^{21}$ As much as $90 \%$ of patients with TMD report poor sleep quality. ${ }^{22,23}$ Evidence that suggests the specific role of disturbed sleep as a causative factor in the pathogenesis of TMD is also accumulating. ${ }^{24,25}$ Several pathological processes may be involved in the interrelationship between sleep problems and TMD as in other pain disorders which include increased sympathetic nervous system activity, immune system dysregulation, and neuroendocrine dysfunction, however the exact mechanism is yet to be elucidated. $^{25-27}$

Despite evidence supporting the close relationship between TMD and sleep disorders only a limited number of previous studies have investigated the occurrence of primary sleep disorders in TMD patients based on objective measures of sleep and such studies were of a relatively small sample size. ${ }^{28-30}$ On the other hand, most studies are focused on assessing the sleep quality in TMD populations based on questionnaires or assessing its possible relationship with sleep bruxism, which is a single disease entity among the various sleep disorders that may be related to TMD. ${ }^{22,23,31,32}$

Considering the general lack of recognition and high percentage of undiagnosed cases leading to the undertreatment of sleep disorders, the current scarcity of data describing the co-occurrence of primary sleep disorders and TMD may have detrimental health consequences resulting from the untimely management of sleep disorders that can initiate and exacerbate TMD and its related symptoms. ${ }^{33}$ The relationship between the two should be examined to identify high-risk patients who are in need of sleep disorder management and provide accurate clinical guidelines for assessing sleep during the diagnostic and treatment process of TMD to prevent poor long-term prognosis from inappropriate levels of multidisciplinary approaches.

Therefore, the objective of this study was to characterize the incidence of well-defined TMD in a large-scale nationwide population-based sample of primary sleep disorder patients by examining the rate of TMD in comorbid sleep disorders relative to the general population as well as other socioeconomic and clinical factors that may have an association with their co-occurrence. We hypothesized that TMD would be substantive in the primary sleep disorder population even after controlling for well-known confounders of TMD.

\section{Patients and Methods Study Design and Population}

This study was designed as a retrospective cohort study and utilized the National Health Insurance ServiceNational Health Screening Cohort (NHIS-HEALS), a cohort of participants registered in the health screening program provided by NHIS of the Republic of Korea from 2002 to 2013. The NHIS-HEALS cohort was composed of 509,900 random samples of individuals aged 40 to 79 , which accounted for $10 \%$ of all health screening participants between 2002 and 2003. ${ }^{34}$ The NHIS has been providing mandatory health insurance for all Koreans since 1989 with approximately 98\% of all Koreans enrolled. ${ }^{35}$ This contains all insurance claim data as well as causes of death, which are identified using a national database and thorough healthcare data for admissions and outpatient visits. All participants are required to undergo standardized health examinations every two years. The health examination database included biological laboratory results such as blood pressure, fasting glucose, lipid profile, hemoglobin, body mass index and waist circumference as well as health-related behavioral variables.

Of the total 509,900 people, 1,620 participants who were diagnosed with a primary sleep disorder in 2002 were excluded to consider only the newly diagnosed cases since 2003. Among these included individuals, 246 participants were excluded because they were diagnosed with TMD before the outset of the follow-up (index date: January 1, 2006). A further 36,451 participants with missing screening data and 2,701 deaths were also excluded. The final study population consisted of 468,882 participants (shown in Figure 1). This study was approved by the Institutional Review Board (IRB) of Seoul National University Hospital 


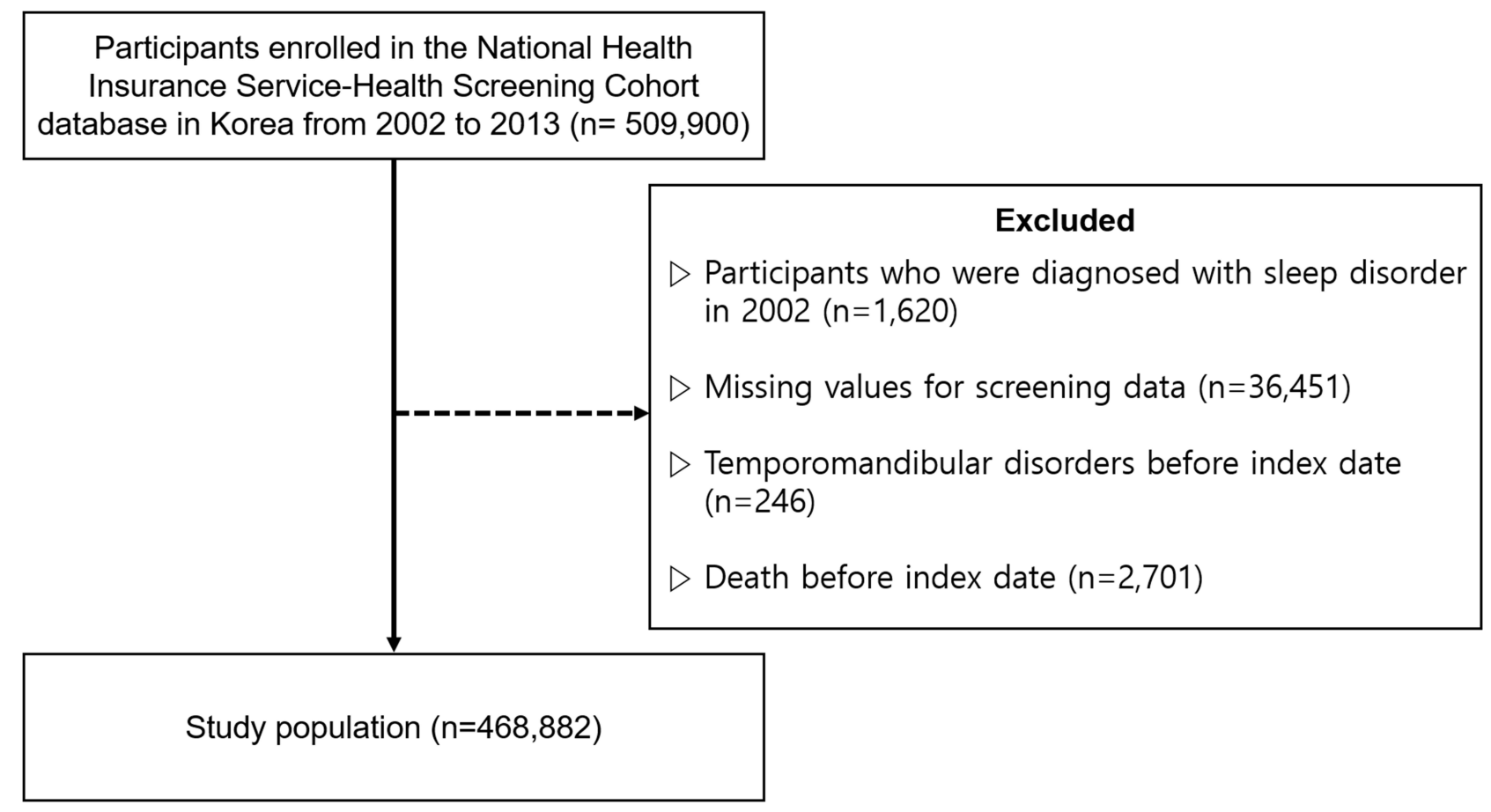

Figure I Flow chart of identifying the study population from the National Health Insurance Service-Health Screening Cohort database of the Republic of Korea.

(IRB Number: 1801-019-912). The IRB granted exemption of informed consent. The data accessed complies with relevant data protection and privacy regulations. All data were anonymized and maintained with confidentiality.

\section{Definition of Clinical Outcomes}

Primary sleep disorders and TMD were defined as a case respectively when the same diagnosis was given at least twice and such diagnoses occurred at intervals of 30 days or more based on the International Classification of Diseases, Tenth Revision (ICD-10). ${ }^{36}$ While this tends to underestimate the frequency of cases compared with other studies, it is a conservative approach to minimize the likelihood of misclassification. ICD-10 codes for primary sleep disorders including G47 sleep disorders (insomnia, hypersomnia, circadian rhythm sleep disorders, sleep apnea, narcolepsy, parasomnia, and sleep-related movement disorders), F51 sleep disorders not due to a substance or known physiological condition (insomnia not due to a substance or known physiological condition, hypersomnia not due to a substance or known physiological condition, sleepwalking, sleep terrors, and nightmare disorder), and G25.8 other specific extrapyramidal and movement disturbances were considered as exposure variables. Restless legs syndrome (G25.81) diagnoses were additionally included and analyzed because it is described as a primary sleep disorder in the International Classification of Sleep Disorders, Third Edition (ICSD-3). ${ }^{37}$

The outcome variable of this study was TMD defined as the existence of an outpatient visit record from January 1, 2006 to December 31, 2013. The ICD-10 code used to diagnose TMD was K07.6 (temporomandibular joint disorders). At the end of follow-up, the survival length was calculated until one of the following three results appeared: (1) diagnosis of TMD; (2) end of 2013; (3) death during follow-up period.

\section{Covariates}

Covariates included age, sex, household income (quartile), smoking (never, $<10,10-29$, and $\geq 30$ years), alcohol consumption ( $<3$, and $\geq 3$ times per week), physical exercise frequency ( $<3$, and $\geq 3$ times per week), hypertension, diabetes mellitus, hyperlipidemia, body mass index (BMI) $(<25$, and $\geq 25)$, and the Charlson Comorbidity Index (CCI) as of before the index year. "How many times a week do you exercise enough to sweat?" was used as a question to verify the frequency of physical exercise. Hypertension was defined as a systolic blood pressure $\geq 140 \mathrm{mmHg}$ or a diastolic blood pressure $\geq 90 \mathrm{mmHg}$. Diabetes mellitus was defined as a fasting blood glucose $\geq 126 \mathrm{mg} / \mathrm{dL}$. Hyperlipidemia was defined as a total cholesterol level $\geq 200 \mathrm{mg} / \mathrm{dL}$ or low density lipoprotein level 
$\geq 130 \mathrm{mg} / \mathrm{dL}$ or triglyceride level $\geq 150 \mathrm{mg} / \mathrm{dL}$. BMI was calculated as weight $(\mathrm{kg})$ divided by the square of height (meter). CCI was used to reflect overall morbidity and calculated by weighting and scoring for comorbid conditions. ${ }^{38}$ Age was treated as a continuous variable and all other variables as categorical variables.

\section{Data Analyses}

To compare the characteristics of the two groups according to the exposure variable, the categorical variable was expressed as a percentage of the population using Pearson chi-square tests, and the continuous variable was expressed as a mean with standard deviation using independent t-tests. We used the Cox proportional hazards regression model after hierarchically adjusting potential confounding factors to compute the hazard ratio (HR) and $95 \%$ confidence interval $(95 \%$ CI $)$ for TMD. Subgroup analysis was done with sex, age, and physical exercise frequency groups to identify potential subgroups with possible associations between sleep disorders and TMD. Statistical significance was defined as a $P$-value $<0.05$. All data collection and statistical analysis were performed using SAS 9.4 (SAS Institute, Cary, NC, USA).

\section{Results}

3,638,524 person-years were analyzed. Table 1 shows descriptive characteristics of the study population. The number of participants with and without primary sleep disorders were 6,999 (1.5\%) and 461,883 (98.5\%), respectively. The mean age was higher for participants with sleep disorders than for those without. Women had significantly more sleep disorders than men. The incidence rate of TMD was almost twice as high in primary sleep disorder patients compared with participants without sleep disorders.

Figure 2 shows the Kaplan-Meier survival curves with Log rank tests for crude causal association of TMD according to the presence of primary sleep disorders. The survival time was significantly shorter for the sleep disorder group (mean survival time, 7.972; 95\% CI, 7.9637.981) than the non-sleep disorder group (mean survival time, 7.986 years; $95 \%$ CI, 7.986-9.987) by Log rank test $(P<0.001)$.

The risk of TMD according to the presence of sleep disorders is shown in Table 2. When all covariates were adjusted as possible confounders of TMD, the participants with sleep disorders had a higher risk for TMD than the non-sleep disorders (aHR 1.44, 95\% CI 1.02-2.04).
Figure 3 shows the results of subgroup analysis stratifying participants by sex, age, and frequency of physical exercise. Although women had more sleep disorders than men, the risk of TMD according to sleep disorders was not statistically different between the sexes. At age 60 and older, participants who had a sleep disorder had a 1.64 times higher risk than participants without a sleep disorder for TMD. In addition, among the participants who exercised three or more times a week, those who suffered from sleep disorders had a twice higher risk for TMD. Sleep disorders were associated with an increased risk of TMD as the participants' age and frequency of physical exercise per week increased.

\section{Discussion}

The results of this nationwide, population-based cohort study showed that primary sleep disorders act as an independent risk factor for TMD and this increased incidence remained significant even after adjusting for well-known confounding factors of TMD including demographic characteristics such as age and sex, and environmental factors such as household income, smoking, alcohol consumption, and physical exercise level. The impact of sleep disorders on TMD was more critical at an older age (age $\geq 60$ years) and for those who exercised above a certain exertion level more often. This is the first large-scale study to demonstrate the prevalence of TMD in a primary sleep disorder population and analyze its effect on TMD occurrence.

Although primary sleep disorders encompass a wide variety of distinct disease entities with different pathophysiologic mechanisms, the most evident consequence shared by all sleep disorders is the disruption and lowering of sleep quality. Sleep is universal to all species, taking up to onethird of a human's lifespan, and is critical for recovery and overall well-being. ${ }^{39}$ Low quality sleep has been associated with a wide range of dysfunctions throughout the whole body system including increased risk of coronary heart disease, ${ }^{40}$ diabetes, ${ }^{41}$ neurological disorders,${ }^{42}$ and psychological disorders such as depression and anxiety. ${ }^{43}$ Increased pain sensitivity is also a well-known phenomenon commonly identified with sleep disruption. It is known that around $50 \%$ of people who report low quality sleep suffer from chronic pain. ${ }^{44}$ Patients with primary insomnia, the most common type of primary sleep disorder, showed lower pain thresholds and attenuated pain inhibition compared with healthy controls. ${ }^{45}$ Sleep apnea, the second most common primary sleep disorder, is also frequently associated with heightened pain sensations ${ }^{46}$ and its treatment through 
Table I Demographic and Clinical Characteristics of the Study Population According to the Presence of Primary Sleep Disorders

\begin{tabular}{|c|c|c|c|}
\hline & $\begin{array}{l}\text { No Sleep } \\
\text { Disorder }\end{array}$ & $\begin{array}{l}\text { Sleep } \\
\text { Disorder }\end{array}$ & $P$ value \\
\hline Number of subjects, n, (\%) & $461,883(98.5)$ & $6,999(1.5)$ & \\
\hline Number of TMD cases, n, (\%) & I, 171 (97.3) & $33(2.7)$ & \\
\hline Incidence rate, $(95 \% \mathrm{Cl}) *$ & $3.3(2.9-3.8)$ & $6.1(5.4-7.1)$ & $<0.001$ \\
\hline Age, years, mean (SD) & $55.4(9.5)$ & $61.0(10.1)$ & $<0.001$ \\
\hline $\begin{array}{l}\text { Sex, \% } \\
\text { Male } \\
\text { Female }\end{array}$ & $\begin{array}{l}53.5 \\
46.5\end{array}$ & $\begin{array}{l}41.6 \\
58.4\end{array}$ & $<0.001$ \\
\hline $\begin{array}{l}\text { Household income, quartile, \% } \\
\text { Ist (highest) } \\
\text { 2nd } \\
\text { 3rd } \\
\text { 4th (lowest) }\end{array}$ & $\begin{array}{l}15.3 \\
21.8 \\
29.0 \\
33.9\end{array}$ & $\begin{array}{l}16.7 \\
22.7 \\
27.4 \\
33.2\end{array}$ & $<0.001$ \\
\hline $\begin{array}{l}\text { Smoking status, } \% \\
\text { Never } \\
<10 \text { years } \\
10-29 \text { years } \\
\geq 30 \text { years }\end{array}$ & $\begin{array}{l}69.5 \\
3.9 \\
7.2 \\
19.4\end{array}$ & $\begin{array}{l}77.1 \\
2.9 \\
4.3 \\
15.7\end{array}$ & $<0.001$ \\
\hline $\begin{array}{l}\text { Alcohol consumption, per week, \% } \\
\text { Never } \\
<3 \text { times } \\
\geq 3 \text { times }\end{array}$ & $\begin{array}{l}58.7 \\
30.4 \\
10.9\end{array}$ & $\begin{array}{l}71.0 \\
20.6 \\
8.4\end{array}$ & $<0.001$ \\
\hline $\begin{array}{l}\text { Physical exercise, per week, \% } \\
\text { Never } \\
<3 \text { times } \\
\geq 3 \text { times }\end{array}$ & $\begin{array}{l}54.1 \\
24.7 \\
21.2\end{array}$ & $\begin{array}{l}58.5 \\
18.4 \\
23.1\end{array}$ & $<0.001$ \\
\hline $\begin{array}{l}\text { Hypertension, \% } \\
\text { No } \\
\text { Yes }\end{array}$ & $\begin{array}{l}70.0 \\
30.0\end{array}$ & $\begin{array}{l}67.0 \\
33.0\end{array}$ & $<0.001$ \\
\hline $\begin{array}{l}\text { Diabetes mellitus, \% } \\
\text { No } \\
\text { Yes }\end{array}$ & $\begin{array}{l}92.0 \\
8.0\end{array}$ & $\begin{array}{l}91.0 \\
9.0\end{array}$ & $<0.001$ \\
\hline $\begin{array}{l}\text { Hyperlipidemia, \% } \\
\text { No } \\
\text { Yes }\end{array}$ & $\begin{array}{l}53.4 \\
46.6\end{array}$ & $\begin{array}{l}50.7 \\
49.3\end{array}$ & $<0.001$ \\
\hline $\begin{array}{r}\text { BMI, \% } \\
<25 \\
\geq 25\end{array}$ & $\begin{array}{l}65.3 \\
34.7\end{array}$ & $\begin{array}{l}65.8 \\
34.2\end{array}$ & 0.315 \\
\hline $\begin{array}{l}\mathrm{CCl}, \% \\
0 \\
1 \\
2 \\
\geq 3\end{array}$ & $\begin{array}{l}14.5 \\
21.7 \\
20.8 \\
43.0\end{array}$ & $\begin{array}{l}3.3 \\
8.6 \\
13.7 \\
74.4\end{array}$ & $<0.001$ \\
\hline
\end{tabular}

Notes: Continuous variables are expressed as mean (SD), and categorical variables as \%. Analysis of variance for continuous variables and Chi-square test for categorical variables. *per $10^{4}$ person-years.

Abbreviations: SD, standard deviation; BMI, body mass index; $\mathrm{CCl}$, Charlson Comorbidity Index; TMD, temporomandibular disorders; $\mathrm{Cl}$, confidence interval. continuous positive airway pressure therapy was shown to reduce pain sensitivity. ${ }^{47}$ The direct relationship between circadian rhythm sleep disorders and pain sensitivity has not yet been investigated, however, a previous study reported that night shift workers exhibited an increased sensitivity to experimentally induced pain. ${ }^{48}$ Interestingly, most studies on the relationship between sleep disorders and pain are focused on the restriction of sleep and less sleep duration while there are no studies that investigate the correlation between hypersomnia and pain. Based on the reports that show idiopathic hypersomnia patients exhibit high levels of sleep fragmentation, ${ }^{49}$ and long sleep time ( $\geq 9$ hours) is associated with increased risk of musculoskeletal pain, ${ }^{50}$ we could assume that more sleep of a lower quality is also a risk factor for increased pain sensitivity. Restless leg syndrome is another primary sleep disorder that has only recently been investigated in relation to pain disorders and the results suggest a common pathophysiology involving disturbed supraspinal pain modulation of the basal ganglia and dopaminergic pathways. ${ }^{51}$

The impact of sleep disorders has already been investigated specifically in the TMD population in previous studies. However, most studies focus on the influence of bruxism as a contributing factor to TMD pain aggravation $^{52}$ and more recently have investigated the relationship between TMD and sleep-related breathing disorders as a single disease entity stating obstructive sleep apnea as a risk factor of developing TMD. ${ }^{53,54}$ The only other primary sleep disorder to be analyzed in relation to TMD is insomnia although the existing literature is scarce in spite of the fact that insomnia disorder is the most frequently diagnosed sleep disorder in TMD patients. ${ }^{29}$ One study reported that insomnia was associated with reduced mechanical and thermal pain thresholds in myofascial TMD patients ${ }^{29}$ and another study showed that the increases in insomnia symptoms were succeeded by increases in average daily TMD pain in the next month. ${ }^{55}$ However, the current literature lacks an accurate characterization of the relationship between primary sleep disorders as a whole and TMD. The results of our analysis support the need to investigate the possibility of TMD and orofacial pain in any primary sleep disorder population that could be experiencing sleep disruption. Such an anticipatory diagnostic approach could take place even before a definitive diagnosis of a specific sleep disorder is given to a patient if the patient complains of low quality sleep. Early diagnosis and active 


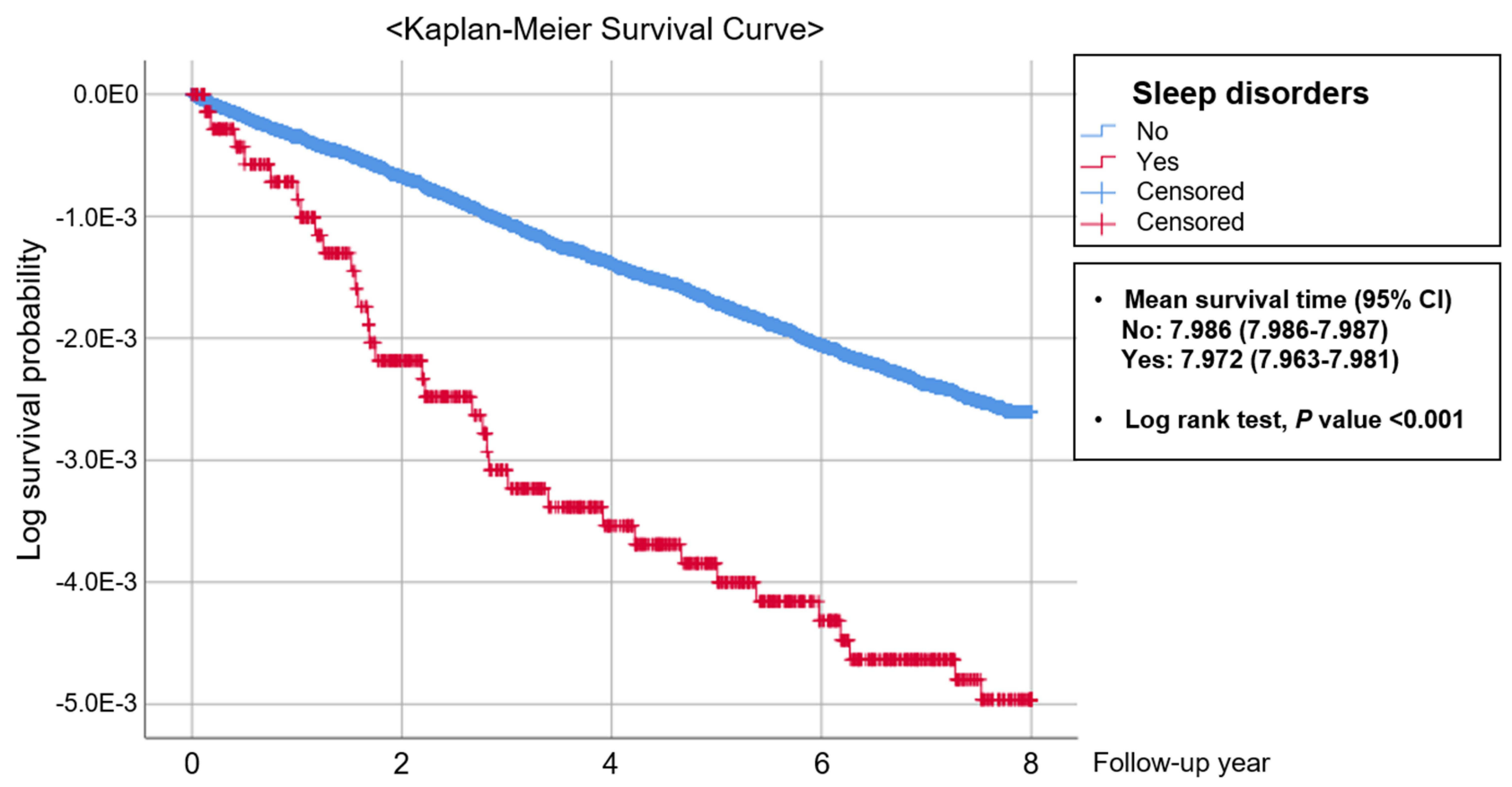

Figure 2 Kaplan-Meier survival curve for log survival probability according to primary sleep disorder on new events of temporomandibular disorders over 8 years followup.

treatment is known to result in better long-term prognosis with pain disorders. ${ }^{56,57}$ Studies on the reciprocal bidirectional relationship between sleep and pain once again highlight the importance of appropriate TMD diagnosis and symptom control since chronic pain could impair sleep quality in turn. ${ }^{58}$ Also some studies suggest the close relationship between the TMJ and systemic conditions. ${ }^{59}$
The presence of a primary sleep disorder may affect the initiation and maintenance of TMD-related symptoms through various mechanisms. Restricted and disturbed sleep is known to cause systemic inflammation. Sleep restriction has been associated with elevated levels of interleukin- $1 \beta^{60}$ while sleep disturbance was correlated to increased circulatory levels of interleukin (IL)-6 and C-reactive protein. ${ }^{61}$ Obstructive sleep apnea patients

Table 2 Hazard Ratios for Temporomandibular Disorders According to the Presence of Primary Sleep Disorders

\begin{tabular}{|l|l|l|}
\hline \multirow{2}{*}{ Temporomandibular Disorders } & Presence of Sleep Disorder & Yes \\
\cline { 2 - 3 } & No & $* 1.55(1.09-2.19)$ \\
\hline $\begin{array}{l}\text { Model I } \\
\text { aHR }(95 \% \mathrm{Cl})\end{array}$ & 1.00 (reference) & \\
\hline $\begin{array}{l}\text { Model } 2 \\
\text { aHR }(95 \% \mathrm{Cl})\end{array}$ & 1.00 (reference) & $* 1.56(1.10-2.20)$ \\
\hline $\begin{array}{l}\text { Model } 3 \\
\text { aHR }(95 \% \mathrm{Cl})\end{array}$ & 1.00 (reference) & $* 1.56(1.10-2.21)$ \\
\hline $\begin{array}{l}\text { Model } 4 \\
\text { aHR }(95 \% \mathrm{Cl})\end{array}$ & 1.00 (reference) & $* 1.44(1.02-2.04)$ \\
\hline
\end{tabular}

Notes: Model I was adjusted for age and sex; model 2 was adjusted for variables included in model I and household income; model 3 was adjusted for variables included in model 2 and smoking status, alcohol consumption, and physical exercise; model 4 was adjusted for variables included in model 3 and hypertension, diabetes mellitus, hyperlipidemia, body mass index, and Charlson comorbidity index. $* P$ indicates a significant difference.

Abbreviations: aHR, adjusted hazard ratio; $\mathrm{Cl}$, confidence interval. 


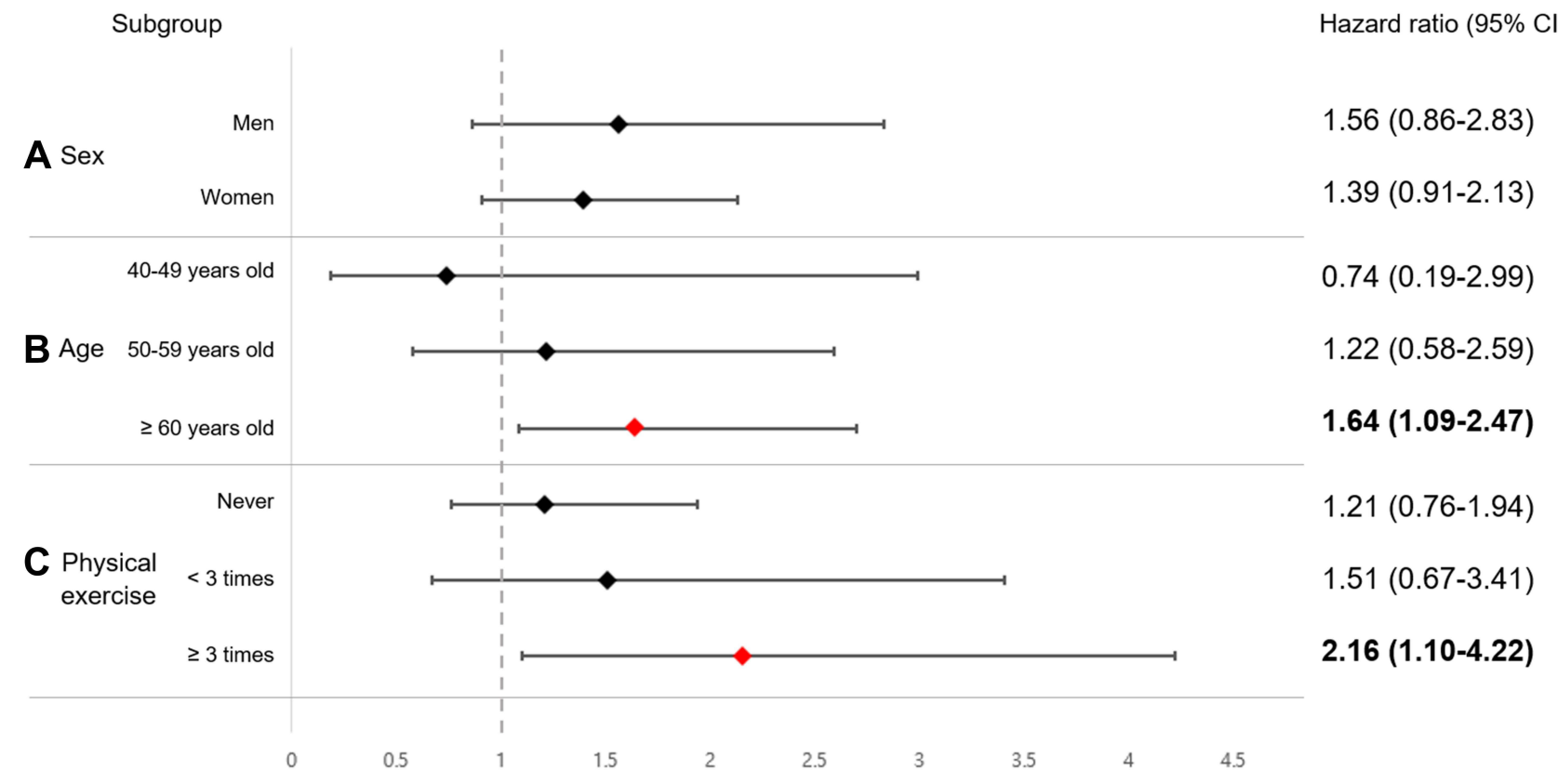

Figure 3 Subgroup analysis of the association between primary sleep disorders and temporomandibular disorders by sex $(\mathbf{A})$, age $(\mathbf{B})$, and physical exercise $(\mathbf{C})$. Bold indicates $P<$ 0.05 .

present with increased levels of inflammatory cytokines including tumor necrosis factor- $\alpha$, IL-6, and IL-8. ${ }^{62}$ Higher plasma levels of inflammatory cytokines were found in TMD patients with lower sleep quality. ${ }^{25}$ Inflammatory cytokines can directly elicit pain through activation of specific receptors on nociceptive sensory neurons and also indirectly through other mediators such as prostanoids and amines. ${ }^{63}$ Another mechanism to consider is the effect of sleep disturbance on psychological conditions. Sleep disturbance is a well-known symptom of depression and more recent studies have identified insomnia as a risk factor of developing depression. ${ }^{64}$ Sleep disturbance has been suggested as an exacerbating factor of anxiety symptoms. ${ }^{65}$ Depression and anxiety are both prominent features of chronic TMD and are fully established contributors to TMD symptom aggravation with studies showing poor sleep quality increasing the level of depression and anxiety in TMD patients. ${ }^{66}$ Interestingly depression and anxiety have also been investigated in regards of chronic systemic inflammation. High pro-inflammatory cytokine levels predicted the risk of developing depression and antiinflammatory medication was effective in controlling depressive symptoms. IL-6 is known to cause increased anxiety levels in mice. ${ }^{67}$ Another pathway to consider in the relationship between primary sleep disorders and TMD is the hypothalamic-pituitary-adrenal (HPA) axis. This mechanism is also involved in the mediation of psychological disorders. Altered HPA axis function has been associated with chronic pain disorders such as fibromyalgia while its normal activity is crucial for maintaining and modulating normal sleep. ${ }^{68}$ Evidence supports increased HPA axis activity in TMD patients with psychological factors such as anxiety and depression contributing to its upregulation. ${ }^{69}$ Another minor mechanism to consider could be sleep bruxism. The role of sleep bruxism has been handled in numerous studies as a risk factor of TMD with conflicting results. ${ }^{31,32}$ On the other hand increased episodes of bruxism were associated with more apneic events in mild to moderate obstructive sleep apnea patients $^{70}$ and insomnia increased the risk of sleep bruxism. ${ }^{71}$ However, due to the lack of sufficient scientific data on both the causality between sleep disorders and TMD with bruxism it is difficult to establish a conclusive relationship and further studies are necessary to investigate common mechanisms.

Another interesting finding of our study is the significant impact of physical exercise frequency on the association between primary sleep disorders and TMD. Those who were diagnosed with a primary sleep disorder and regularly exercised 3 or more times a week were exposed to a significantly increased risk of TMD. The results are in line with a recent study that first explored the relationship between general physical activity and TMD with the results showing that moderate-intensity exercise compared 
with low-intensity exercise was associated with a significantly higher risk of TMD pain while lowintensity exercise significantly decreased such a risk. ${ }^{72}$ The interaction between physical activity and sleep is complex with numerous factors including sex, age, exercise type, duration, and compliance moderating the relationship. ${ }^{73}$ Generally, poor sleep quality is associated with low physical activity level. ${ }^{74}$ However due to the lack of a standardized approach in defining and measuring physical activity level and the heterogeneity among studies related to the age, sex, and psychological status of the study group it is difficult to directly compare the results from distinctive studies. A previous study that sought the role of sleep disturbance in the association between physical activity and prospective pain onset showed that those that experienced sleep disturbance with a high frequency did not benefit from increased physical activity suggesting that the frequency of sleep disturbance is a decisive factor in the interrelationship between physical activity and pain. ${ }^{75}$ In our study a primary sleep disorder was defined as a case when the same diagnosis was given at least twice and such diagnoses occurred at intervals of 30 days or more to avoid possible misclassification. This could have resulted in a study population with a relatively more severe level of sleep disorders which could explain the harmful effect of higher exercise levels observed in the results. Several studies on pain disorders including low back pain and fibromyalgia report the deleterious effect of high levels of physical exercise on pain exacerbation. ${ }^{76,77}$ Fatigue could be the factor that is related to the increased incidence of TMD in primary sleep disorder patients with higher physical activity levels. Fatigue was reported as a significant mediator of the relationship between sleep disturbance and musculoskeletal pain severity $^{74}$ and naturally fatigue is independently associated with high-intensity exercise in patients with widespread pain. $^{76}$

The results of our study showed that older age was another factor that increased the risk of TMD in primary sleep disorder patients. This is interesting considering the fact that the prevalence of TMD peaks in young adults (20-40 years old). ${ }^{1}$ However, a previous study showed that peak incidence of TMD differs according to the specific subgroup diagnosis of TMD with inflammatory degenerative joint disorders appearing more frequently at an older age. $^{78}$ Unfortunately, TMD subgroup diagnosis information was not obtainable in this study hindering the evaluation of its effect on age-related differences in primary sleep disorder and TMD associations. The prevalence and severity of common sleep disorders including insomnia and obstructive sleep apnea are known to increase with age and suggests the possibility that higher levels of sleep disorders increase the risk of TMD more significantly. ${ }^{79,80}$ Disordered sleep is also known to have a physical and psychological impact in adolescents. This age range was not included in this study and requires additional investigations. ${ }^{81}$

There are several limitations of this study that need to be considered. First, uncontrolled factors could exist due to the lack of information in the database. Second, this study was based on major diagnoses and was unable to differentiate with dual diagnoses that could affect TMD. Third, the stringent criteria for primary sleep disorder and TMD diagnoses could have resulted in underestimation of each disease, thus influencing the final results. Despite such limitations, there are several strengths of this study. The large sample size representative of Koreans was sufficient to provide accurate results. Selection bias was minimized by using a cohort consisting of a general population randomly selected for $10 \%$ of all health screening results without matching cases and controls. In addition, many known confounding factors were controlled and primary sleep disorder and TMD were strictly defined and screened. Furthermore, the long-term follow-up period provides evidence for a possible causal relationship between primary sleep disorders and TMD. It is noteworthy that this investigation was based on definitive diagnoses of primary sleep disorders and not sleep disturbance per se as in the majority of studies analyzing the relationship between sleep related problems and TMD. Such a real-life approach provides a more clinically oriented picture of the close association between primary sleep disorders and TMD and supports the need for active investigations of TMD and orofacial pain in the primary sleep disorder population.

\section{Conclusion}

This large population-based cohort study showed a significantly higher incidence of TMD in those diagnosed with primary sleep disorders. The results suggest the need to actively screen for TMD and orofacial painrelated issues in primary sleep disorder patients to prevent the adverse effect of uncontrolled sleep disorder prognosis on pain. An interdisciplinary approach should be taken to properly manage combined issues of TMD and sleep disorder along with their comorbid conditions. 
Further clinical studies of a prospective longitudinal design are needed to clearly elucidate the relationship and causality between primary sleep disorders and TMD. The effect of early diagnosis and control of TMD and orofacial pain on long-term prognosis of sleep disorders should also be investigated to truly understand the value of recognizing TMD problems in the primary sleep disorder population. Additionally, studies based on specific sleep disorder diagnoses such as insomnia and obstructive sleep apnea are necessary to further elucidate the causal relationship between independent sleep disorders and TMD and suggest more detailed clinical guidelines.

\section{Ethics Approval}

The Institutional Review Board (IRB) of Seoul National University Hospital approved this study (IRB Number: 1801-019-912), which is in compliance with the World Medical Association Declaration of Helsinki of 1975, as revised in 2008. The IRB granted exemption of informed consent. The data accessed complies with relevant data protection and privacy regulations. All data were anonymized and maintained with confidentiality.

\section{Acknowledgment}

This study was based on the NHIS-HEALS data (NHIS2017-2-439), which was prepared by the Korean National Health Insurance Service.

\section{Funding}

This work was supported by the National Research Foundation of Korea (NRF) grant funded by the Korean government (MSIT) (No. 2020R1C1C1013322).

\section{Disclosure}

All authors declare no potential conflicts of interest for this work, nor with respect to the authorship and publication of this article.

\section{References}

1. de Leeuw R, Klasser GD; AAOP. Orofacial Pain: Guidelines for Assessment, Diagnosis, and Management. 6thed. Quintessence Publishing Company, Incorporated; 2018

2. Maixner W, Fillingim RB, Williams DA, Smith SB, Slade GD. Overlapping chronic pain conditions: implications for diagnosis and classification. J Pain. 2016;17(9 Suppl):T93-t107. doi:10.1016/j. jpain.2016.06.002

3. Barros Vde M, Seraidarian PI, Côrtes MI, de Paula LV. The impact of orofacial pain on the quality of life of patients with temporomandibular disorder. J Orofac Pain. 2009;23(1):28-37.
4. Ohrbach R, Bair E, Fillingim RB, et al. Clinical orofacial characteristics associated with risk of first-onset TMD: the OPPERA prospective cohort study. J Pain. 2013;14(12 Suppl):T33-50. doi:10.1016/j. jpain.2013.07.018

5. Merrill RL. Orofacial Pain and Sleep. Sleep Med Clin. 2010;5 (1):131-144. doi:10.1016/j.jsmc.2009.10.008

6. Luyster FS, Strollo PJ Jr, Zee PC, Walsh JK. Sleep: a health imperative. Sleep. 2012;35(6):727-734. doi:10.5665/sleep.1846

7. Xi B, He D, Zhang M, Xue J, Zhou D. Short sleep duration predicts risk of metabolic syndrome: a systematic review and meta-analysis. Sleep Med Rev. 2014;18(4):293-297. doi:10.1016/j.smrv.2013.06.001

8. Calhoun DA, Harding SM. Sleep and hypertension. Chest. 2010;138 (2):434-443. doi:10.1378/chest.09-2954

9. Walia HK, Li H, Rueschman M, et al. Association of severe obstructive sleep apnea and elevated blood pressure despite antihypertensive medication use. J Clin Sleep Med. 2014;10(8):835-843.

10. Qie R, Zhang D, Liu L, et al. Obstructive sleep apnea and risk of type 2 diabetes mellitus: a systematic review and dose-response meta-analysis of cohort studies. J Diabetes. 2020;12(6):455-464. doi:10.1111/1753-0407.13017

11. Li M, Zhang XW, Hou WS, Tang ZY. Insomnia and risk of cardiovascular disease: a meta-analysis of cohort studies. Int $J$ Cardiol. 2014;176(3):1044-1047. doi:10.1016/j.ijcard.2014.07.284

12. He C, Anand ST, Ebell MH, Vena JE, Robb SW. Circadian disrupting exposures and breast cancer risk: a meta-analysis. Int Arch Occup Environ Health. 2015;88(5):533-547. doi:10.1007/s00420014-0986-x

13. Palamaner Subash Shantha G, Kumar AA, Cheskin LJ, Pancholy SB. Association between sleep-disordered breathing, obstructive sleep apnea, and cancer incidence: a systematic review and meta-analysis. Sleep Med. 2015;16(10):1289-1294. doi:10.1016/j.sleep.2015.04.014

14. Lu Y, Tian N, Yin J, Shi Y, Huang Z. Association between sleep duration and cancer risk: a meta-analysis of prospective cohort studies. PLoS One. 2013;8(9):e74723. doi:10.1371/journal. pone. 0074723

15. Kovacs FM, Seco J, Royuela A, et al. The association between sleep quality, low back pain and disability: a prospective study in routine practice. Eur J Pain. 2018;22(1):114-126. doi:10.1002/ejp.1095

16. Choy EH. The role of sleep in pain and fibromyalgia. Nat Rev Rheumatol. 2015;11(9):513-520. doi:10.1038/nrrheum.2015.56

17. Roizenblatt M, Rosa Neto NS, Tufik S, Roizenblatt S. Pain-related diseases and sleep disorders. Braz J Med Biol Res. 2012;45 (9):792-798. doi:10.1590/S0100-879X2012007500110

18. Brand S, Gerber M, Pühse U, Holsboer-Trachsler E. The relation between sleep and pain among a non-clinical sample of young adults. Eur Arch Psychiatry Clin Neurosci. 2010;260(7):543-551. doi:10.1007/s00406-010-0113-2

19. Blågestad T, Pallesen S, Grønli J, Tang NK, Nordhus IH. How Perceived Pain Influence Sleep and Mood More Than The Reverse: a Novel, Exploratory Study with Patients Awaiting Total Hip Arthroplasty. Front Psychol. 2016;7:1689. doi:10.3389/ fpsyg.2016.01689

20. Nijs J, Mairesse O, Neu D, et al. Sleep Disturbances in Chronic Pain: neurobiology, Assessment, and Treatment in Physical Therapist Practice. Phys Ther. 2018;98(5):325-335. doi:10.1093/ptj/pzy020

21. Mathias JL, Cant ML, Burke ALJ. Sleep disturbances and sleep disorders in adults living with chronic pain: a meta-analysis. Sleep Med. 2018;52:198-210. doi:10.1016/j.sleep.2018.05.023

22. Yatani H, Studts J, Cordova M, Carlson CR, Okeson JP. Comparison of sleep quality and clinical and psychologic characteristics in patients with temporomandibular disorders. J Orofac Pain. 2002;16 (3):221-228.

23. Rener-Sitar K, John MT, Pusalavidyasagar SS, Bandyopadhyay D, Schiffman EL. Sleep quality in temporomandibular disorder cases. Sleep Med. 2016;25:105-112. doi:10.1016/j.sleep.2016.06.031 
24. Sanders AE, Akinkugbe AA, Fillingim RB, et al. Causal Mediation in the Development of Painful Temporomandibular Disorder. J Pain. 2017;18(4):428-436. doi:10.1016/j.jpain.2016.12.003

25. Park JW, Chung JW. Inflammatory Cytokines and Sleep Disturbance in Patients with Temporomandibular Disorders. J Oral Facial Pain Headache. 2016;30(1):27-33. doi:10.11607/ofph.1367

26. Mullington JM, Haack M, Toth M, Serrador JM, Meier-Ewert HK. Cardiovascular, inflammatory, and metabolic consequences of sleep deprivation. Prog Cardiovasc Dis. 2009;51(4):294-302. doi:10.1016/ j.pcad.2008.10.003

27. Medic G, Wille M, Hemels ME. Short- and long-term health consequences of sleep disruption. Nat Sci Sleep. 2017;9:151-161. doi:10.2147/NSS.S134864

28. Smith MT, Wickwire EM, Grace EG, et al. Sleep disorders and their association with laboratory pain sensitivity in temporomandibular joint disorder. Sleep. 2009;32(6):779-790. doi:10.1093/sleep/ 32.6.779

29. Edwards RR, Grace E, Peterson S, Klick B, Haythornthwaite JA, Smith MT. Sleep continuity and architecture: associations with pain-inhibitory processes in patients with temporomandibular joint disorder. Eur J Pain. 2009;13(10):1043-1047. doi:10.1016/j. ejpain.2008.12.007

30. Dubrovsky B, Raphael KG, Lavigne GJ, et al. Polysomnographic investigation of sleep and respiratory parameters in women with temporomandibular pain disorders. J Clin Sleep Med. 2014;10 (2):195-201.

31. Ohlmann B, Waldecker M, Leckel M, et al. Correlations between Sleep Bruxism and Temporomandibular Disorders. J Clin Med. 2020;9:2. doi:10.3390/jcm9020611

32. Raphael KG, Sirois DA, Janal MN, et al. Sleep bruxism and myofascial temporomandibular disorders: a laboratory-based polysomnographic investigation. J Am Dent Assoc. 2012;143(11):1223-1231. doi:10.14219/jada.archive.2012.0068

33. Rosen RC, Zozula R, Jahn EG, Carson JL. Low rates of recognition of sleep disorders in primary care: comparison of a community-based versus clinical academic setting. Sleep Med. 2001;2(1):47-55. doi:10.1016/S1389-9457(00)00043-5

34. Seong SC, Kim YY, Park SK, et al. Cohort profile: the National Health Insurance Service-National Health Screening Cohort (NHIS-HEALS) in Korea. BMJ Open. 2017;7(9):e016640. doi:10.1136/bmjopen-2017-016640

35. Kwon S. Thirty years of national health insurance in South Korea: lessons for achieving universal health care coverage. Health Policy Plan. 2009;24(1):63-71. doi:10.1093/heapol/czn037

36. World Health Organization. The International Classification of Diseases, 10th Rev.: ICD-10. Geveva, Switzerland: World Health Organization; 2004.

37. Medicine AAoS. International Classification of Sleep Disorders. American Academy of Sleep Medicine; 2014.

38. Charlson ME, Pompei P, Ales KL, MacKenzie CR. A new method of classifying prognostic comorbidity in longitudinal studies: development and validation. $J$ Chronic Dis. 1987;40(5):373-383. doi:10.1016/0021-9681(87)90171-8

39. Keenan SA. Normal human sleep. Respir Care Clin N Am. 1999;5 (3):319-331.

40. Lao XQ, Liu X, Deng HB, et al. Sleep Quality, Sleep Duration, and the Risk of Coronary Heart Disease: a Prospective Cohort Study With 60,586 Adults. J Clin Sleep Med. 2018;14(1):109-117. doi:10.5664/ jcsm. 6894

41. Lee SWH, Ng KY, Chin WK. The impact of sleep amount and sleep quality on glycemic control in type 2 diabetes: a systematic review and meta-analysis. Sleep Med Rev. 2017;31:91-101. doi:10.1016/j. smrv.2016.02.001

42. Zhang Y, Ren R, Sanford LD, et al. Sleep in Parkinson's disease: a systematic review and meta-analysis of polysomnographic findings. Sleep Med Rev. 2020;51:101281. doi:10.1016/j.smrv.2020.101281
43. Okun ML, Mancuso RA, Hobel CJ, Schetter CD, Coussons-Read M. Poor sleep quality increases symptoms of depression and anxiety in postpartum women. J Behav Med. 2018;41(5):703-710. doi:10.1007/ s10865-018-9950-7

44. Taylor DJ, Mallory LJ, Lichstein KL, Durrence HH, Riedel BW, Bush AJ. Comorbidity of chronic insomnia with medical problems. Sleep. 2007;30(2):213-218. doi:10.1093/sleep/30.2.213

45. Haack M, Scott-Sutherland J, Santangelo G, Simpson NS, Sethna N, Mullington JM. Pain sensitivity and modulation in primary insomnia. Eur J Pain. 2012;16(4):522-533. doi:10.1016/j.ejpain.2011.07.007

46. Terzi R, Y1lmaz Z. Evaluation of pain sensitivity by tender point counts and myalgic score in patients with and without obstructive sleep apnea syndrome. Int $J$ Rheum Dis. 2017;20(3):340-345. doi:10.1111/1756-185X.12629

47. Khalid I, Roehrs TA, Hudgel DW, Roth T. Continuous positive airway pressure in severe obstructive sleep apnea reduces pain sensitivity. Sleep. 2011;34(12):1687-1691. doi:10.5665/sleep.1436

48. Matre D, Knardahl S, Nilsen KB. Night-shift work is associated with increased pain perception. Scand J Work Environ Health. 2017;43 (3):260-268. doi:10.5271/sjweh.3627

49. Pizza F, Ferri R, Poli F, Vandi S, Cosentino FI, Plazzi G. Polysomnographic study of nocturnal sleep in idiopathic hypersomnia without long sleep time. J Sleep Res. 2013;22(2):185-196. doi:10.1111/j.1365-2869.2012.01061.x

50. Chun MY, Cho BJ, Yoo SH, Oh B, Kang JS, Yeon C. Association between sleep duration and musculoskeletal pain: the Korea National Health and Nutrition Examination Survey 2010-2015. Medicine. 2018;97(50):e13656. doi:10.1097/MD.0000000000013656

51. Holman AJ, Myers RR. A randomized, double-blind, placebo-controlled trial of pramipexole, a dopamine agonist, in patients with fibromyalgia receiving concomitant medications. Arthritis Rheum. 2005;52(8):2495-2505. doi:10.1002/art.21191

52. Jiménez-Silva A, Peña-Durán C, Tobar-Reyes J, Frugone-Zambra R. Sleep and awake bruxism in adults and its relationship with temporomandibular disorders: a systematic review from 2003 to 2014. Acta Odontol Scand. 2017;75(1):36-58. doi:10.1080/ 00016357.2016 .1247465

53. Wu JH, Lee KT, Kuo CY, et al. The Association between Temporomandibular Disorder and Sleep Apnea-A Nationwide Population-Based Cohort Study. Int J Environ Res Public Health. 2020;17:17. doi:10.3390/ijerph17176311

54. Sanders AE, Essick GK, Fillingim R, et al. Sleep apnea symptoms and risk of temporomandibular disorder: OPPERA cohort. $J$ Dent Res. 2013;92(7 Suppl):70s-77s. doi:10.1177/0022034513488140

55. Quartana PJ, Wickwire EM, Klick B, Grace E, Smith MT. Naturalistic changes in insomnia symptoms and pain in temporomandibular joint disorder: a cross-lagged panel analysis. Pain. 2010;149 (2):325-331. doi:10.1016/j.pain.2010.02.029

56. Molde Hagen E, Grasdal A, Eriksen HR. Does early intervention with a light mobilization program reduce long-term sick leave for low back pain: a 3-year follow-up study. Spine. 2003;28(20):2309-2315. doi:10.1097/01.BRS.0000085817.33211.3F

57. Larson MJ, Adams RS, Ritter GA, et al. Associations of Early Treatments for Low-Back Pain with Military Readiness Outcomes. J Altern Complement Med. 2018;24(7):666-676. doi:10.1089/ acm.2017.0290

58. Andersen ML, Araujo P, Frange C, Tufik S. Sleep Disturbance and Pain: a Tale of Two Common Problems. Chest. 2018;154 (5):1249-1259. doi:10.1016/j.chest.2018.07.019

59. Fiorillo L, Musumeci G. TMJ Dysfunction and Systemic Correlation. J Funct Morphol Kinesiol. 2020;5(1):20. doi:10.3390/jfmk5010020

60. Tartar JL, Fins AI, Lopez A, et al. Sleep restriction and delayed sleep associate with psychological health and biomarkers of stress and inflammation in women. Sleep Health. 2015;1(4):249-256. doi:10.1016/j.sleh.2015.09.007 
61. Irwin MR, Olmstead R, Carroll JE. Sleep Disturbance, Sleep Duration, and Inflammation: a Systematic Review and Meta-Analysis of Cohort Studies and Experimental Sleep Deprivation. Biol Psychiatry. 2016;80(1):40-52. doi:10.1016/j. biopsych.2015.05.014

62. Nadeem R, Molnar J, Madbouly EM, et al. Serum inflammatory markers in obstructive sleep apnea: a meta-analysis. J Clin Sleep Med. 2013;9(10):1003-1012. doi:10.5664/jcsm.3070

63. Cook AD, Christensen AD, Tewari D, McMahon SB, Hamilton JA. Immune Cytokines and Their Receptors in Inflammatory Pain. Trends Immunol. 2018;39(3):240-255. doi:10.1016/j.it.2017.12.003

64. Fang H, Tu S, Sheng J, Shao A. Depression in sleep disturbance: a review on a bidirectional relationship, mechanisms and treatment. J Cell Mol Med. 2019;23(4):2324-2332. doi:10.1111/jcmm.14170

65. Cox RC, Olatunji BO. A systematic review of sleep disturbance in anxiety and related disorders. J Anxiety Disord. 2016;37:104-129. doi:10.1016/j.janxdis.2015.12.001

66. Ekici Ö. Association of stress, anxiety, and depression levels with sleep quality in patients with temporomandibular disorders. Cranio. 2020;1-9. doi:10.1080/08869634.2020.1861886

67. Peirce JM, Alviña K. The role of inflammation and the gut microbiome in depression and anxiety. J Neurosci Res. 2019;97 (10):1223-1241. doi:10.1002/jnr.24476

68. Buckley TM, Schatzberg AF. On the interactions of the hypothalamic-pituitary-adrenal (HPA) axis and sleep: normal HPA axis activity and circadian rhythm, exemplary sleep disorders. J Clin Endocrinol Metab. 2005;90(5):3106-3114.

69. Staniszewski K, Lygre H, Bifulco E, et al. Temporomandibular Disorders Related to Stress and HPA-Axis Regulation. Pain Res Manag. 2018;2018:7020751. doi:10.1155/2018/7020751

70. Martynowicz H, Gac P, Brzecka A, et al. The Relationship between Sleep Bruxism and Obstructive Sleep Apnea Based on Polysomnographic Findings. J Clin Med. 2019;8:10. doi:10.3390/ jcm8101653

71. Maluly M, Dal Fabbro C, Andersen ML, Herrero Babiloni A, Lavigne GJ, Tufik S. Sleep bruxism and its associations with insomnia and OSA in the general population of Sao Paulo. Sleep Med. 2020;75:141-148. doi:10.1016/j.sleep.2020.06.016
72. Cho HJ, Kim SJ, Park SE, Park JW. Physical activity level and temporomandibular disorders in South Koreans. Community Dent Oral Epidemiol. 2020;48(3):225-231. doi:10.1111/cdoe.12519

73. Kredlow MA, Capozzoli MC, Hearon BA, Calkins AW, Otto MW. The effects of physical activity on sleep: a meta-analytic review. J Behav Med. 2015;38(3):427-449. doi:10.1007/s10865-015-9617-6

74. Vancampfort D, Stubbs B, Smith L, et al. Physical activity and sleep problems in 38 low- and middle-income countries. Sleep Med. 2018;48:140-147. doi:10.1016/j.sleep.2018.04.013

75. Whibley D, Guyer HM, Swanson LM, Braley TJ, Kratz AL, Dunietz GL. Sleep disturbance as a moderator of the association between physical activity and later pain onset among American adults aged 50 and over: evidence from the Health and Retirement Study. BMJ Open. 2020;10(6):e036219. doi:10.1136/bmjopen-2019-036219

76. van Santen M, Bolwijn P, Landewé R, et al. High or low intensity aerobic fitness training in fibromyalgia: does it matter? $J$ Rheumatol. 2002;29(3):582-587.

77. Jones GT, Watson KD, Silman AJ, Symmons DP, Macfarlane GJ. Predictors of low back pain in British schoolchildren: a population-based prospective cohort study. Pediatrics. 2003;111(4 Pt 1):822-828. doi:10.1542/peds.111.4.822

78. Manfredini D, Piccotti F, Ferronato G, Guarda-Nardini L. Age peaks of different RDC/TMD diagnoses in a patient population. J Dent. 2010;38(5):392-399. doi:10.1016/j.jdent.2010.01.006

79. Cao XL, Wang SB, Zhong BL, et al. The prevalence of insomnia in the general population in China: a meta-analysis. PLoS One. 2017;12 (2):e0170772. doi:10.1371/journal.pone.0170772

80. Leppänen T, Töyräs J, Mervaala E, Penzel T, Kulkas A. Severity of individual obstruction events increases with age in patients with obstructive sleep apnea. Sleep Med. 2017;37:32-37. doi:10.1016/j. sleep.2017.06.004

81. Brand S, Kirov R. Sleep and its importance in adolescence and in common adolescent somatic and psychiatric conditions. Int $J$ Gen Med. 2011;4:425-442
International Journal of General Medicine

\section{Publish your work in this journal}

The International Journal of General Medicine is an international, peer-reviewed open-access journal that focuses on general and internal medicine, pathogenesis, epidemiology, diagnosis, monitoring and treatment protocols. The journal is characterized by the rapid reporting of reviews, original research and clinical studies

\section{Dovepress}

across all disease areas. The manuscript management system is completely online and includes a very quick and fair peer-review system, which is all easy to use. Visit http://www.dovepress.com/ testimonials.php to read real quotes from published authors. 